\title{
Coherency and Thermal Evolution of Metastable and Stable $\beta$ Phase Precipitates in Aluminum Alloy AA5456
}

\author{
Daniel Foley ${ }^{1}$, Andrew Lang ${ }^{1}$, Mitra L. Taheri ${ }^{1}$ and Asher Leff ${ }^{2}$ \\ 1. Department of Materials Science and Engineering, Drexel University, Philadelphia, PA. \\ 2. Army Research Lab, ALC - Energy and Power Division, Adelphi, MD.
}

The 5xxx series of aluminum alloys, with the primary alloying element magnesium, are attractive candidates to replace structural steels due to their high strength-to-weight ratio, good weldability, and good corrosion resistance. At contents of greater than $3 \mathrm{wt} . \% \mathrm{Mg}$, these alloys are susceptible to sensitization, which here refers to the growth of grain boundary $\beta$ precipitates (composition $\mathrm{Al}_{3} \mathrm{Mg}_{2}$ ) after aging at moderate temperatures, from roughly $50-300^{\circ} \mathrm{C}$. As $\beta$ is anodic to the matrix, sensitized material is susceptible to intergranular stress corrosion cracking (IGSCC) [1]. Many studies have demonstrated the negative bulk mechanical and corrosion effects of sensitization, and more recent efforts have sought to understand how and where $\beta$ precipitates though use of electron microscopy.

Several studies utilizing digital scanning calorimetry (DSC) and x-ray diffraction (XRD) have shown an evolution of phases preceding the formation of the equilibrium phase [2] [3]. Significantly, these studies show that at low sensitization temperatures (such as those likely to be encountered in service conditions) it is not the equilibrium phase that forms, but precursor phases such as $\beta$ ' ' $\left(\mathrm{Al}_{3} \mathrm{Mg}\right)$ and $\beta$ ' (also $\left.\mathrm{Al}_{3} \mathrm{Mg}_{2}\right)$. Yet many studies looking at the bulk mechanical and corrosion effects of sensitization make little or no delineation between the equilibrium and metastable phases, labeling any precipitation as $\beta$ precipitation. The present work uses transmission electron microscopy (TEM) methods to investigate the thermal evolution and growth habits of $\beta$ and its related phases. Recrystallized aluminum alloy AA5456 was sensitized at 100,250 , and $325^{\circ} \mathrm{C}$, and analyzed in a JEOL $2100 \mathrm{~F}$ TEM. Energy dispersive $\mathrm{x}$-ray spectroscopy (EDS) and high-resolution (HR) TEM was used for phase identification. Additionally, HRTEM was used to determine the matrix-precipitate orientation relationship. Finally, precession electron diffraction (PED) was utilized to measure any interfacial strain arising from coherency relationships.

Investigation of precipitates in the $100^{\circ} \mathrm{C}$ sensitization treatment revealed the presence of the $\beta$ ' phase. There is a relative deficiency of $\mathrm{Mg}$ in the EDS spectrum when compared those of the other two sensitization treatments, consistent with the stoichiometry of expected phases. Furthermore, the HR-TEM of the $100^{\circ} \mathrm{C}$ precipitate revealed a much less complicated structure than the other two. This is consistent with $\beta$ ' ' being thought to possess the ordered fcc $\left(\mathrm{L}_{2}\right)$ structure. The orientation relationship observed is a coherent interface along the [100] direction, consistent with previous descriptions of the phase, though the elongated morphology differs [4].

The equilibrium $\beta$ and metastable $\beta$ ' have complex fcc and complex hexagonal structures, respectively, each with well over 1000 atoms per unit cell [5]. This complexity is apparent in the HR-TEM images and associated fast Fourier transforms (FFTs) of the two higher temperature precipitates. Their EDS spectra demonstrate a similar abundance of $\mathrm{Mg}$ with respect to $\mathrm{Al}$, as both are expected to have the same chemical composition. The $250^{\circ} \mathrm{C}$ treatment yielded a precipitate that grew out of the $\{021\}$ plane of the matrix and the $325^{\circ} \mathrm{C}$ precipitate grew out of the $\{110\}$ plane of the matrix. Growth of $\beta$-equilibrium out of the $\{110\}$ planes has been observed by other researchers, but $\{021\}$ growth has not [6]. This suggests that the $250^{\circ} \mathrm{C}$ precipitate is indeed $\beta$ '. 
Precession electron diffraction was done on the $100^{\circ} \mathrm{C}$ and $325^{\circ} \mathrm{C}$ precipitates to investigate the existence of any interfacial strains in the matrix. The low temperature precipitate induced a small strain $(\sim 0.002)$ on the matrix, which is expected, as the crystal structure of $\beta$ ', is essentially that of the matrix with significantly higher $\mathrm{Mg}$ content. The $325^{\circ} \mathrm{C}$ precipitate demonstrated a higher strain of roughly 0.008 indicating that this phase is coherent with the matrix, as opposed to semi-coherent. A drop to negative strain before leveling off to zero was observed for both precipitates. This could represent a relative depletion of $\mathrm{Mg}$ close to the precipitate.

These experiments make it clear that the precipitation processes of $\beta$ and its related phases is quite complex, and that in-service sensitization may be caused by phases other than $\beta$-equilibrium. More research must be done on these metastable phases to understand the affect they have on mechanical and corrosion properties. Furthermore, making sensitization-resistant materials will be quite complicated as the various phases have significantly different precipitation behavior.

\section{References:}

[1] J. R. Davis, Corrosion of Aluminum and Aluminum Alloys. ASM International (1999).

[2] N. R and I. S, Transactions of the Japan Institute of Metals 21(9) (1980), p. 580.

[3] K. Osamura and T. Ogura, Metall. Trans. A 15(May) (1984), p. 835.

[4] D. A, B. E. K, and R. M, Scr. Metall. 10(2) (1976), p. 4.

[5] W. Steurer, Zeitschrift für Krist. 222(227) (2007), p. 259.

[6] Y. Zhao et al, Scr. Mater. 89 (2014), p. 49.
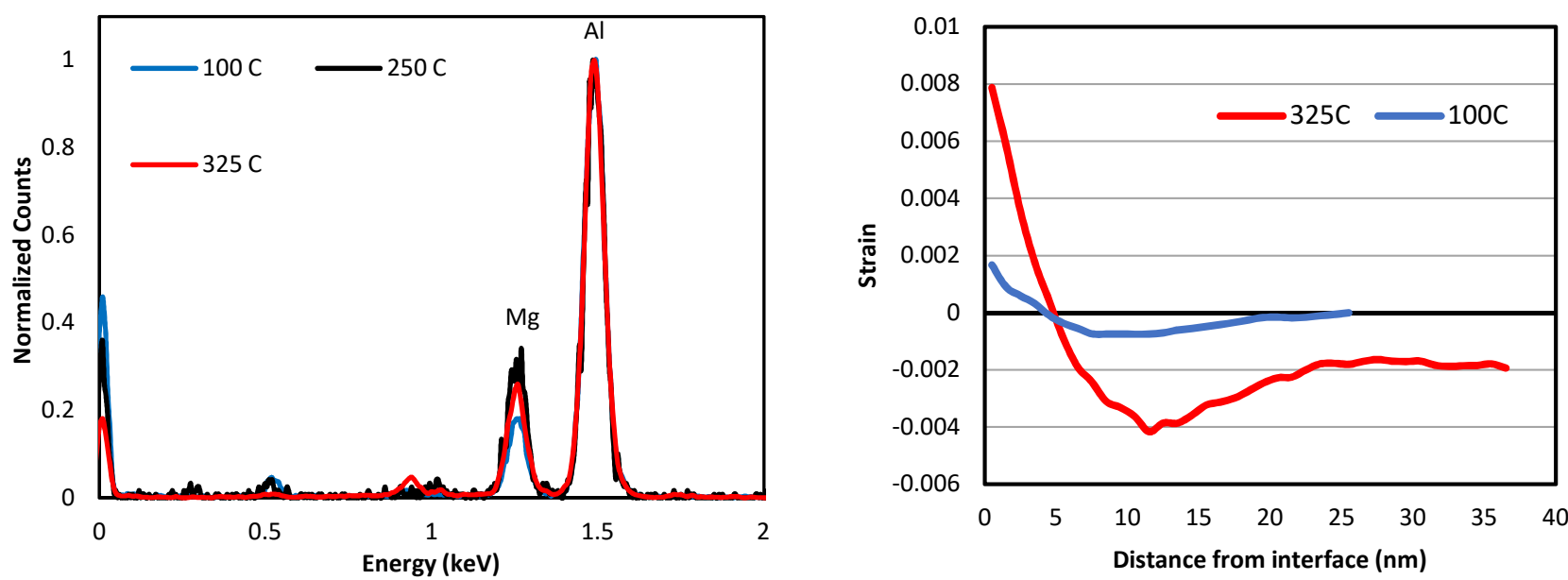

Figure 1. Left, EDS spectra of precipitates grown at three sensitization temperatures. Note the lower relative $\mathrm{Mg}$ content in the $100 \mathrm{C}$ spectrum. Right, strain profiles moving away from $\beta$-matrix interface 